\title{
CRESCIMENTO, NUTRIÇÃO MINERAL E NÍVEL CRÍTICO FOLIAR DE P EM MUDAS DE UMBUZEIRO, EM FUNÇÃ̃ DA ADUBAÇÃO FOSFATADA ${ }^{1}$
}

\author{
ORLANDO SÍLVIOCAÍRES NEVES², JANICE GUEDES DECARVALHO ${ }^{3}$, \\ ERIC VICTOR DE OLIVEIRA ${ }^{4}$, VANESSABRITO FERNANDES NEVES ${ }^{5}$
}

RESUMO-O crescimento, a nutrição mineral e o nível crítico foliar de $\mathrm{P}$ em mudas de umbuzeiro crescidas em vasos contendo amostras de um Latossolo Vermelho distroférrico, em função da adubação fosfatada, foram avaliados neste trabalho. O delineamento experimental utilizado foi o de blocos casualizados, com quatro repetições e seis doses de $\mathrm{P}\left(0 ; 30 ; 60 ; 120 ; 240 \mathrm{e} 480 \mathrm{mg} \mathrm{dm}^{-3}\right)$. A adubação fosfatada foi realizada numa única aplicação, antes do transplantio das mudas. Observa-se que a dose de $281 \mathrm{mg} \mathrm{dm}^{-3}$ de $\mathrm{P}$ proporcionou a máxima produção de matéria seca das mudas de umbuzeiro, e, mesmo quando bem nutrido em $\mathrm{P}$, o umbuzeiro apresentou maior produção de matéria seca do sistema radicular do que na parte aérea. A faixa crítica de $\mathrm{P}$ nas folhas das mudas do umbuzeiro é de 1,52 a $1,91 \mathrm{~g} \mathrm{~kg}^{-1}$.

Termos para indexação: umbu, fertilização e Spondias tuberosa.

\section{GROWTH, MINERAL NUTRITION AND FOLIAR CRITICAL LEVEL OF P IN 'UMBUZEIRO’ SEEDLINGS, AS A FUNCTION OF PHOSPHORUS FERTILIZATION}

\begin{abstract}
This work was accomplished in order to evaluate the growth, the mineral nutrition and the foliar critical level of P in 'umbuzeiro' seedlings, grown in pots containing distroferric Red Latosol, in function of phosphorus fertilization. The experimental design was randomized blocks with four replications and six doses of $\mathrm{P}\left(0,30,60,120,240\right.$ and $\left.480 \mathrm{mg} \mathrm{dm}^{-3}\right)$. The phosphorus fertilization was done in just one application, before the transplant of the seedlings. The dose of $281 \mathrm{mg} \mathrm{dm}^{-3}$ of P provided the highest production of dry matter of the 'umbuzeiro' seedlings. Even when well nourished with $\mathrm{P}$, the 'umbuzeiro' accumulated more organic matter in the root than shoot. The level critical of $\mathrm{P}$ in the leaves of the umbuzeiro seedlings range from 1.52 to $1.91 \mathrm{~g} \mathrm{~kg}^{-1}$.
\end{abstract}

Index terms: 'umbu', fertilization and Spondias tuberose.

\section{INTRODUÇÃO}

O umbuzeiro (Spondias tuberosa Arr. Cam.) é uma frutífera adaptada a sobreviver e produzir sob condição de estresse hídrico. Apesar de sua distribuição ser dispersa, consagra-se como uma espécie frutífera de grande importância econômica, social e ecológica para o semi-árido nordestino (SILVA et al., 1987). A comercialização dos frutos, colhidos de forma extrativista, representa uma fonte de renda importante para muitas famílias nordestinas, chegando a contribuir com até a metade da renda média anual das mesmas (GONDIM et al., 1991). Assim, pode-se pensar no umbuzeiro como uma alternativa viável para o desenvolvimento agrícola da região semi-árida do Nordeste do Brasil.

NEVES (2003), embasado em citações de vários autores, relata a escassez de estudos sobre o umbuzeiro. Até então, apesar da importância que essa planta apresenta para os sertanejos, existem poucos trabalhos publicados, destacadamente na área da nutrição mineral.

O fósforo desempenha importante papel na respiração vegetal e no armazenamento, transporte e utilização de energia no processo fotossintético, agindo também na síntese das proteínas e no metabolismo de enzimas, sendo um elemento essencial para o metabolismo das plantas, principalmente na fase reprodutiva (RAIJ, 1991).

A baixa disponibilidade de $\mathrm{P}$ nos solos tropicais é uma das causas que mais limitam o crescimento e a produção das culturas, tornando necessário o fornecimento desse nutriente via adubação (RAIJ, 1991; FERNANDES et al., 2000).

No umbuzeiro deficiente em $\mathrm{P}$, as folhas mais velhas apresentam coloração amarelada nas bordas. Ainda, há alteração na arquitetura das plantas, ou seja, o ângulo dos ramos plagiotrópicos fica mais fechado em relação ao ramo ortotrópico, no sentido da base para o ápice. As raízes crescem mais, sendo esse um mecanismo do umbuzeiro para sobreviver e produzir em solos pobres em $\mathrm{P}$, como naqueles em que sua ocorrência é natural (CARVALHO et al., 2004; CARVALHO \& NEVES, 2004).

A determinação dos requerimentos nutricionais e a diagnose nutricional das plantas são baseadas na expectativa de que haja estreita correlação entre a disponibilidade do nutriente no solo, o teor do elemento na folha e a produção (MALAVOLTA et al., 1997). Os valores de níveis críticos na parte aérea das plantas, mais propriamente nas folhas, são amplamente utilizados

1(Trabalho 253-07). Recebido em: 25-10-2007. Aceito para publicação em: 29-05-2008.

${ }^{2}$ Professor Adjunto da UFRPE/UAG. Av. Bom Pastor, s/n. Bairro Boa Vista - Garanhuns-PE. CEP 55.296.901. e-mail: silvio@uag.ufrpe.br. ${ }^{3}$ Professora Titular do DCS/UFLA. CP 37, Lavras-MG - CEP 37.200-000. e-mail: janicegc@ufla.br

${ }^{4}$ Graduando em Agronomia UFLA/DCS. CP 37, Lavras-MG - CEP 37.200-000. e-mail: ericsolos@ yahoo.com.br

${ }^{5}$ Mestre em Estatística e Experimentação Agropecuária. Av. Rui Barbosa, 490-A - Heliópolis / Garanhuns-PE. CEP 55.296-230. e-mail: vbfufla@yahoo.com.br 
como padrões na interpretação dos resultados de análises foliares.

O objetivo deste trabalho foi avaliar o crescimento, a nutrição mineral e o nível crítico foliar de $\mathrm{P}$ em mudas de umbuzeiro crescidas em vasos contendo amostras de um Latossolo Vermelho distroférrico, em função da adubação fosfatada.

\section{MATERIAL E MÉTODOS}

O experimento foi realizado em casa de vegetação da área experimental do Departamento de Ciência do Solo da Universidade Federal de Lavras (Lavras-MG), definida geograficamente pelas coordenadas de $21^{\circ} 14^{\prime}$ de latitude sul e $45^{\circ} 00^{\prime}$ de longitude oeste, com altitude de $910 \mathrm{~m}$, sendo conduzido de julho de 2004 a fevereiro de 2005 , com período de crescimento das plantas nos vasos, após o transplantio, de 150 dias.

$\mathrm{O}$ delineamento experimental utilizado foi o de blocos casualizados, com quatro repetições e seis doses de $\mathrm{P}(0 ; 30 ; 60$; 120; 240 e $480 \mathrm{mg} \mathrm{dm}^{-3}$ ). A parcela foi composta por vaso com capacidade para $8 \mathrm{dm}^{3}$, com altura de $50 \mathrm{~cm}$, preenchidos com Latossolo Vermelho distroférrico, cuja caracterização química se encontra na Tabela 1, com uma planta por vaso.

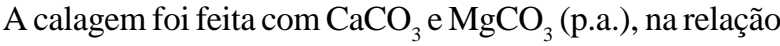
3:1 (Ca: $\mathrm{Mg})$, visando à elevação do nível de saturação por bases a $80 \%$ (NEVES et al., 2004b). Depois de peneirado, o solo foi misturado ao corretivo e incubado por quinze dias. As doses de fósforo foram incorporadas ao solo logo após o período de incubação e numa única aplicação, tendo como fontes o MAP e o fosfato de potássio. A adubação complementar, em $\mathrm{mg} \mathrm{dm}^{-3}$, incluindo o $\mathrm{N}$ e o $\mathrm{K}$ aplicados quando da adubação fosfatada, foi a seguinte: $\mathrm{N}=300 ; \mathrm{K}=300 ; \mathrm{S}=60 ; \mathrm{B}=0,5 ; \mathrm{Cu}=1,5 ; \mathrm{Zn}=5,0 \mathrm{e}$ $\mathrm{Mo}=0,1$ (NEVES et al., 2004a).

A reposição de umidade foi feita diariamente, utilizandose de água deionizada para elevar a $60 \%$ o volume total de poros, sendo o volume a ser adicionado determinado através de pesagens dos vasos.

As sementes passaram pelo processo de quebra de dormência através de escarificação mecânica, conforme recomendação de NASCIMENTO et al. (2000), e foram germinadas em vermiculita. Após 20 dias da emergência, as mudas com altura média de $9,5 \mathrm{~cm}$ foram transplantadas para vasos com os tratamentos.

Ao final do experimento, foram avaliados a altura $(\mathrm{cm})$ e o diâmetro do caule ( $\mathrm{mm}$ ); depois de colhido, o material vegetal foi separado em raízes, caule e folhas, lavado em água corrente e destilada, seco em estufa a $70^{\circ} \mathrm{C}$ até peso constante, e a matéria seca correspondente a cada uma das partes foi pesada (g planta ${ }^{-1}$ ) e moída; em seguida, foram realizadas as determinações químicas para os teores dos nutrientes no caule e nas folhas.

Através do extrato nítrico-perclórico, foram determinados os teores de $\mathrm{P}$ por colorimetria; $\mathrm{Ca}, \mathrm{Mg}, \mathrm{Cu}, \mathrm{Fe}, \mathrm{Mn}$ e $\mathrm{Zn}$ por espectrofotometria de absorção atômica; K e Na por fotometria de chama; $\mathrm{S}$ por turbidimetria do sulfato de bário; $\mathrm{N}$ total pelo método semimicro Kjeldahl; e os teores de B, após digestão por via seca, foram determinados por colorimetria (método da curcumina) (MALAVOLTA et al., 1997).
A partir dos teores dos nutrientes e com base na matéria seca das plantas, calculou-se o acúmulo dos elementos na parte aérea das mudas de umbuzeiro (somatório do acúmulo no caule e nas folhas).

Os dados obtidos foram submetidos à análise de variância, mediante significância do teste $F$, e, quando significativos, realizaram-se análises de regressão. As análises de variância e de regressão foram feitas com o auxílio do programa estatístico SISVAR (FERREIRA, 2000).

O nível crítico foliar de $\mathrm{P}$ foi obtido estimando-se a dose de $\mathrm{P}$ aplicada ao solo, que proporcionou a produção de $90 \%$ da matéria seca das mudas de umbuzeiro e aquela acima do ponto de máxima eficiência física, que proporcionou uma redução de $10 \%$ na produção. Em seguida, essas doses foram substituídas na equação de regressão para os teores foliares de P, obtendose, assim, uma faixa correspondente ao nível crítico desse nutriente.

\section{RESULTADOS E DISCUSSÃO}

\section{Crescimento}

As doses de $\mathrm{P}$ aplicadas ao solo influenciaram significativamente na altura, no diâmetro do caule, na matéria seca de raiz, caule, folha e total e não influenciaram na relação parte aérea / raiz, que manteve média de 0,61, independentemente da dose de P. Essa relação indica que as mudas de umbuzeiro, mesmo crescidas no solo com níveis adequados de fósforo, concentraram compostos orgânicos mais nas raízes do que na parte aérea.

Pelos resultados apresentados na Figura 1, pode-se observar que, para todas as medidas analisadas (diâmetro do caule, altura de plantas, matéria seca das folhas, matéria seca do caule, matéria seca das raízes e matéria seca total), a resposta à adubação fosfatada foi quadrática, ou seja, houve resposta positiva incrementando a produção dessas variáveis à medida que se aumentaram as doses de fósforo aplicadas ao solo; a partir de doses maiores, a resposta à adubação passou a decrescer.

Nas doses de 289 e $250 \mathrm{mg} \mathrm{dm}^{-3}$ de $\mathrm{P}$, foram obtidos a máxima altura das mudas do umbuzeiro e o máximo diâmetro do caule, respectivamente (Figura $1 \mathrm{a}, \mathrm{b}$ ).

Para a matéria seca das folhas e do caule (Figura $1 \mathrm{c}$ ), as doses de 293 e $254 \mathrm{mg} \mathrm{dm}^{-3} \mathrm{de} \mathrm{P}$ foram as que possibilitaram às mudas de umbuzeiro atingir suas máximas produções, respectivamente.

A matéria seca de raiz (Figura $1 \mathrm{~d}$ ) apresentou sua máxima produção física $\left(9,43 \mathrm{~g}_{\text {planta }}{ }^{-1}\right)$ com a dose calculada de $296 \mathrm{mg}$ $\mathrm{dm}^{-3}$ de P. Considerando que parte do $\mathrm{P}$ adicionado foi fixado pelo solo e que a dose necessária para atingir $90 \%(8,49 \mathrm{~g}) \mathrm{da}$ produção foi de $176 \mathrm{mg} \mathrm{dm}^{-3}$, provavelmente, em solos em que esse fenômeno (fixação) é menor, a necessidade da adubação fosfatada para a produção de mudas de umbuzeiro pode ser reduzida.

A dose de $281 \mathrm{mg} \mathrm{dm}^{-3}$ de $\mathrm{P}$ proporcionou uma produção de matéria seca total de 15,51 $\mathrm{g}$ planta $^{-1}$ de umbuzeiro (Figura 1 d); já na dose de $168 \mathrm{mg} \mathrm{dm}^{-3}$, foram obtidos $90 \%$ da máxima produção física $\left(13,96 \mathrm{~g} \mathrm{planta}^{-1}\right)$. 
Analisando a relação percentual entre as três partes estudadas (matéria seca de raiz, caule e folhas) na dose de máxima produção de matéria seca total, observou-se maior produção de massa seca do sistema radicular $(60,3 \%)$ em detrimento à do caule $(25,4 \%)$ e das folhas $(14,3 \%)$, sendo essa relação mantida na dose que proporcionou a produção de $90 \%$ da matéria seca total. Esse resultado pode ser explicado pela adaptação natural do umbuzeiro a ambientes de estresse hídrico e de baixa disponibilidade de $\mathrm{P}$.

De forma geral, todas as medidas de matéria seca estudadas tiveram comportamentos muito semelhantes, apresentando seus pontos de máxima eficiência física entre 250 e $296 \mathrm{mg} \mathrm{dm}^{-3}$ de P. Diversos autores, a exemplo de GUPTA (1982) e NEVES et al. (2004a), relatam efeitos antagônicos entre o P e o $\mathrm{Zn}$, segundo os quais a aplicação de fósforo ao solo reduz a disponibilidade de zinco. Entretanto, nas condições deste experimento, o efeito relatado por esses autores não foi observado.

\section{Teores de macro e micronutrientes}

$\mathrm{O}$ aumento das doses de $\mathrm{P}$ aplicadas ao solo influenciou significativamente nos teores foliares de $\mathrm{P}, \mathrm{Ca}, \mathrm{Mg}$ e $\mathrm{S}$ e não influenciou nos teores de $\mathrm{N}, \mathrm{P}, \mathrm{K}, \mathrm{Ca}, \mathrm{Mg}$ e $\mathrm{S}$ no caule e de $\mathrm{N}$ e $\mathrm{K}$ nas folhas das mudas de umbuzeiro.

Nas folhas, os teores médios de $\mathrm{N}$ e $\mathrm{K}$ foram, respectivamente, de $23,88 \mathrm{~g} \mathrm{~kg}^{-1} \mathrm{e} 5,91 \mathrm{~g} \mathrm{~kg}^{-1}$. No caule, os teores médios foram 10,92 $\mathrm{g} \mathrm{kg}^{-1} \mathrm{de} \mathrm{N} ; 0,53 \mathrm{~g} \mathrm{~kg}^{-1}$ de P; $4,85 \mathrm{~g} \mathrm{~kg}^{-1} \mathrm{de} \mathrm{K}$; $6,60 \mathrm{~g} \mathrm{~kg}^{-1} \mathrm{de} \mathrm{Ca} ; 0,73 \mathrm{~g} \mathrm{~kg}^{-1} \mathrm{de} \mathrm{Mg,e} 0,31 \mathrm{~g} \mathrm{~kg}^{-1} \mathrm{de} \mathrm{S}$.

Com a maior disponibilidade de P no solo, advinda da adubação fosfatada, as mudas de umbuzeiro concentraram mais fósforo nas folhas, sendo os teores aumentados de forma linear (Figura 2 a). $\mathrm{O}$ teor foliar de $\mathrm{P}$ encontrado nas plantas do tratamento $0 \mathrm{mg} \mathrm{dm}^{-3} \mathrm{de} \mathrm{P}$ foi de $1,23 \mathrm{~g} \mathrm{~kg}^{-1}$, enquanto nas plantas do tratamento que recebeu $480 \mathrm{mg} \mathrm{dm}^{-3} \mathrm{de} \mathrm{P}$, o teor foliar foi de $2,06 \mathrm{~g} \mathrm{~kg}^{-1}$, representando aumento de $68 \%$. FERNANDES et al. (2000), estudando espécies florestais, e BONFIM et al. (2004), em Brachiaria brizantha, constataram o mesmo efeito daquele observado para os teores de P no umbuzeiro, ou seja, maiores doses de $\mathrm{P}$ aplicadas ao solo proporcionaram maiores teores foliares desse nutriente.

$\mathrm{Na}$ dose que proporcionou a maior produção de matéria seca, o teor foliar de P nas mudas de umbuzeiro foi de $1,72 \mathrm{~g} \mathrm{~kg}^{-1}$, sendo inferior ao encontrado por SILVA et al. (1984) para umbuzeiros adultos $\left(2,30 \mathrm{~g} \mathrm{~kg}^{-1}\right)$. Para SANTOS (1999), depois da disponibilidade do nutriente no solo, a idade fisiológica do tecido amostrado é considerado o fator mais importante a afetar a composição mineral das plantas.

Segundo MARSCHNER (1995), o requerimento de P para o bom desenvolvimento das culturas, de forma geral, está na faixa de 3 a $5 \mathrm{~g} \mathrm{~kg}^{-1}$. Esse é um dado que indica que o umbuzeiro apresenta baixa exigência em $\mathrm{P}$ se comparado com outras culturas, embora, como verificado na Figura 1, o fornecimento de $\mathrm{P}$ ao solo estimule seu crescimento. Já MALAVOLTA et al. (1997) apresentam valores na faixa de 1,2 a 4,0 $\mathrm{g} \mathrm{kg}^{-1}$ para a maioria das culturas tropicais. Nesse último caso, os valores detectados estão dentro da faixa estabelecida, ainda que tendendo para o limite inferior.

Os teores de $\mathrm{Ca}$ e $\mathrm{Mg}$ nas folhas das mudas do umbuzeiro aumentaram de forma linear em função do fósforo aplicado ao solo (Figura $2 \mathrm{~b}, \mathrm{c}$ ). Na dose em que as plantas acumularam mais matéria, os teores de Ca e $\mathrm{Mg}$ foram de 34,42 $\mathrm{g} \mathrm{kg}^{-1}$ e 3,54 $\mathrm{g} \mathrm{kg}^{-1}$, respectivamente

O comportamento de resposta para os teores foliares de $\mathrm{S}$ (Figura $2 \mathrm{~d}$ ) foi inverso ao comportamento verificado no acúmulo de matéria seca, retratando um efeito de diluição, comportamento idêntico ao verificado para os teores foliares de $\mathrm{Cu}$ (Figura $2 \mathrm{e}$ ).

Os teores foliares de B, Fe, Mn e Zn e os de B, Cu, Fe, Mn e $\mathrm{Zn}$ no caule das mudas do umbuzeiro não foram influenciados pela adubação fosfatada. Os teores foliares médios encontrados foram de 47,27 $\mathrm{mg} \mathrm{kg}^{-1} \mathrm{de} \mathrm{B} ; 167,87 \mathrm{mg} \mathrm{kg}^{-1} \mathrm{de} \mathrm{Fe} ; 211,84 \mathrm{mg} \mathrm{kg}$ ${ }^{1}$ de Mn, e 13,36 $\mathrm{mg} \mathrm{kg}^{-1}$ de Zn. Já no caule, os teores de B, Cu, Fe, Mn e Zn foram de $16,12 \mathrm{mg} \mathrm{kg}^{-1} ; 2,14 \mathrm{mg} \mathrm{kg}^{-1} ; 9,60 \mathrm{mg} \mathrm{kg}^{-1} ; 35,52$ $\mathrm{mg} \mathrm{kg}^{-1}$, e $6,37 \mathrm{mg} \mathrm{kg}^{-1}$, respectivamente.

\section{Nível crítico foliar de $P$}

A Figura 3 traz a ilustração da faixa crítica determinada através da substituição na equação de regressão para os teores foliares de $\mathrm{P}$, das doses para atingir $90 \%$ da produção da matéria seca e da dose acima do ponto de máxima produção física, que reduziu em $10 \%$ a produção. Essa faixa corresponde ao nível crítico foliar de $\mathrm{P}$ nas mudas de umbuzeiro, sendo a mesma de 1,52 a $1,91 \mathrm{~g} \mathrm{~kg}^{-1}$. Assim, valores inferiores a $1,52 \mathrm{~g} \mathrm{~kg}^{-1} \mathrm{de} P$ nas folhas dos umbuzeiros na fase de muda podem ser considerados baixos, e acima de $1,91 \mathrm{~g} \mathrm{~kg}^{-1}$, podem ser considerados altos, $\mathrm{o}$ que pode indicar deficiência ou excesso desse nutriente, respectivamente.

Esses valores estão dentro da faixa mencionada por MALAVOLTA et al. (1997) para a maioria das plantas tropicais $\left(1,2\right.$ a $\left.4,0 \mathrm{~g} \mathrm{~kg}^{-1}\right)$.

O estádio de crescimento tem influência direta sobre os teores de P nas planta. No caso específico desse experimento, salienta-se que o nível crítico foliar de $\mathrm{P}$ em umbuzeiro foi determinado para a fase de muda, sendo necessários mais estudos para sua determinação em outras fases de crescimento, sobretudo em condições de campo.

TABELA 1 - Análise química do solo (Latossolo Vermelho distroférrico) utilizado no experimento*.

\begin{tabular}{|c|c|c|c|c|c|c|c|c|c|c|c|c|}
\hline $\mathrm{pH}$ & $\mathrm{K}$ & $\mathrm{Ca}$ & $\mathrm{Mg} \quad \mathrm{Al}$ & $\mathrm{H}+\mathrm{Al}$ & $\mathrm{MO}$ & $\mathrm{Zn}$ & $\mathrm{Fe}$ & $\mathrm{Mn}$ & $\mathrm{Cu}$ & B & ${\mathrm{S}-\mathrm{SO}^{-}}_{4}$ & $\mathrm{~V}$ \\
\hline $\mathrm{H}_{2} \mathrm{O}$ & $\mathrm{mg} \mathrm{dm}{ }^{-3}$ & & $\mathrm{cmol}_{\mathrm{c}} \mathrm{dm}^{-3}$ & & dag $\mathrm{kg}^{-1}$ & & & & $\mathrm{dm}^{-3}$ & & & $\%$ \\
\hline 4,9 & $1,2 \quad 13$ & 0,7 & 0,2 & 7,0 & 3,0 & 1,2 & 47,3 & 4,8 & 1,5 & 0,4 & 8,9 & 13,3 \\
\hline
\end{tabular}



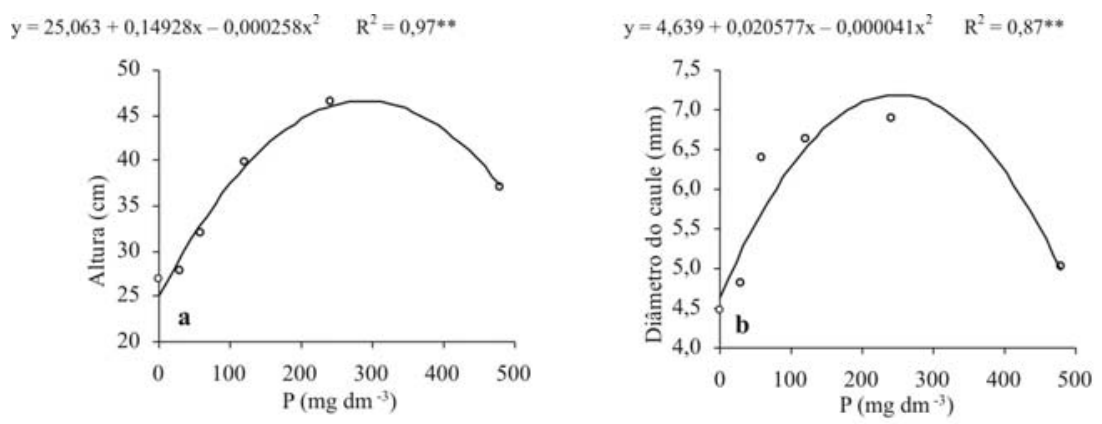
$\begin{array}{cc}\operatorname{MSC}(0) y=1,634+0,01832 x-0,000036 x^{2} & R^{2}=0,86^{* * *} \\ \text { MSF() } y=0,517+0,01172 x-0,00002 x^{2} & R^{2}=0,90^{* *}\end{array}$

MST(o) $y=5,855+0,06864 x-0,000122 x^{2} \quad R^{2}=0,96 *$ $\begin{array}{ll}\text { MSR() } y=3,705+0,038593 x-0,000065 x^{2} & R^{2}=0,99^{*}\end{array}$
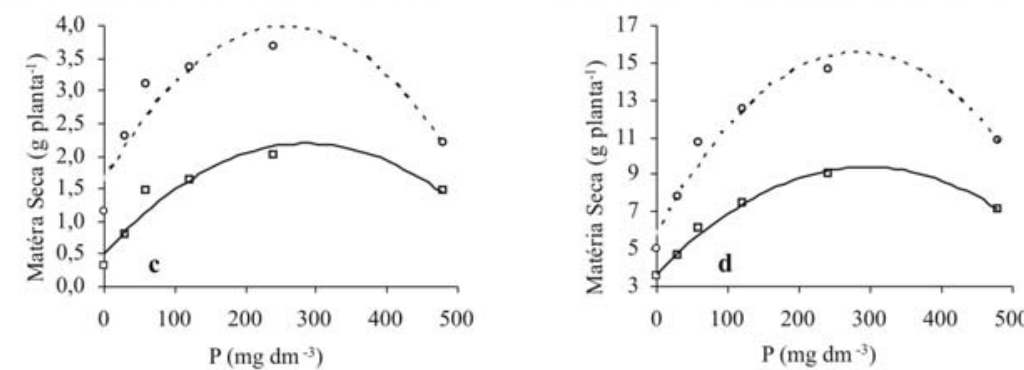

FIGURA 1- Altura (a), diâmetro do caule (b), matéria seca do caule-MSC e matéria seca das folhas-MSF (c), matéria seca das raízesMSR e matéria seca total-MST (d) de mudas de umbuzeiro, em função de doses de fósforo.
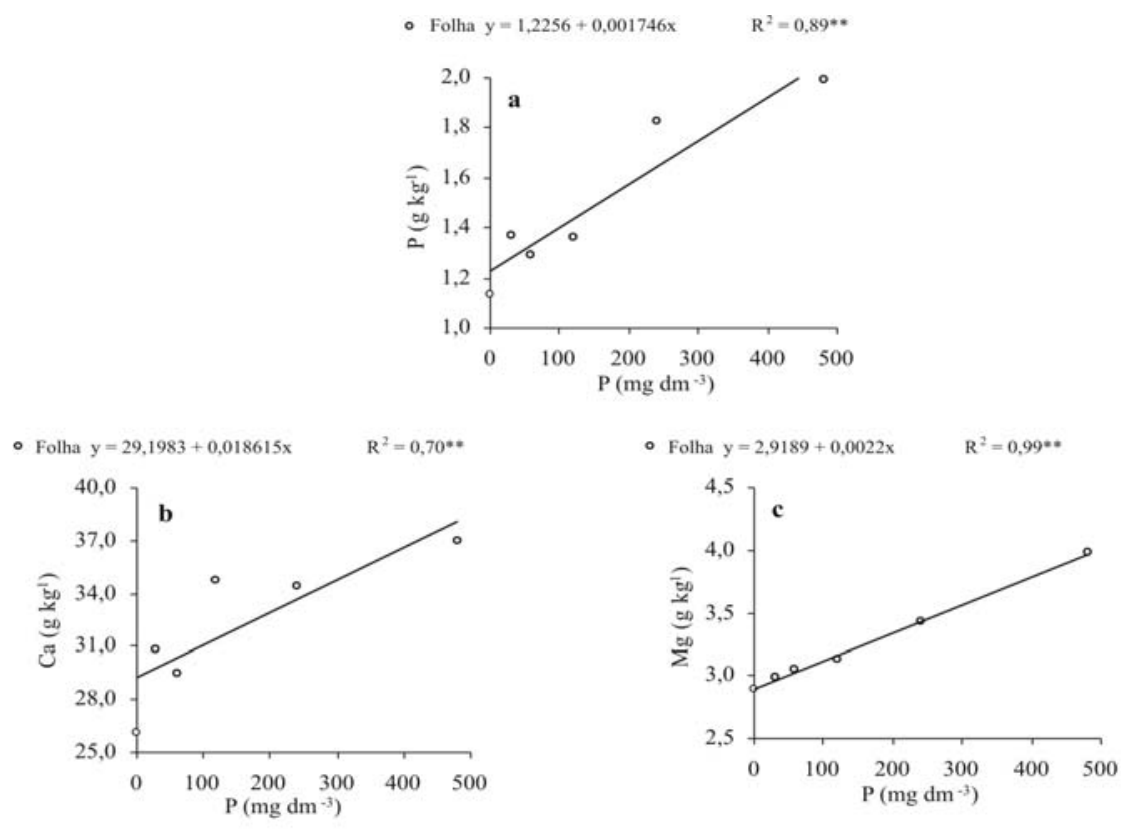

- Folha $y=10,060-0,061652 x+0,000101 x^{2} \quad R^{2}=0,51^{*}$
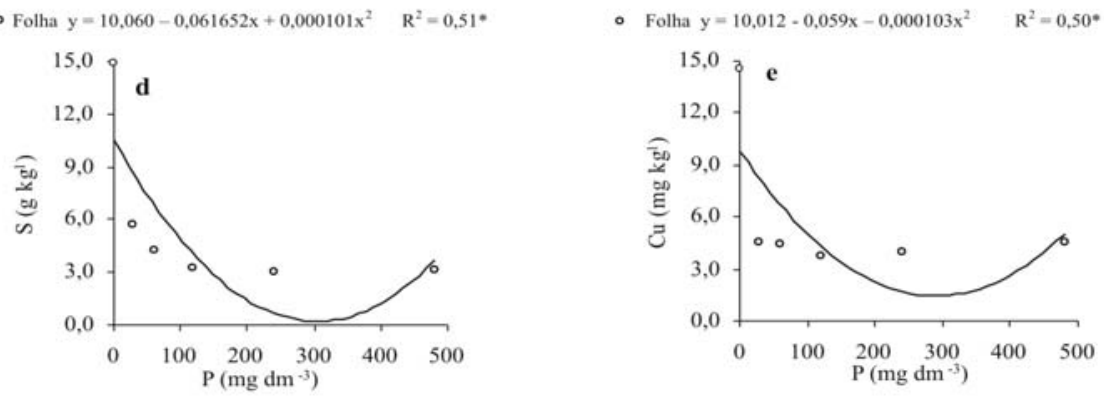

FIGURA 2 -Teores de fósforo (a), cálcio (b), magnésio (c), enxofre (d) e cobre (e) em mudas de umbuzeiros, em função de doses de P. Rev. Bras. Frutic., Jaboticabal - SP, v. 30, n. 3, p. 801-805, Setembro 2008 


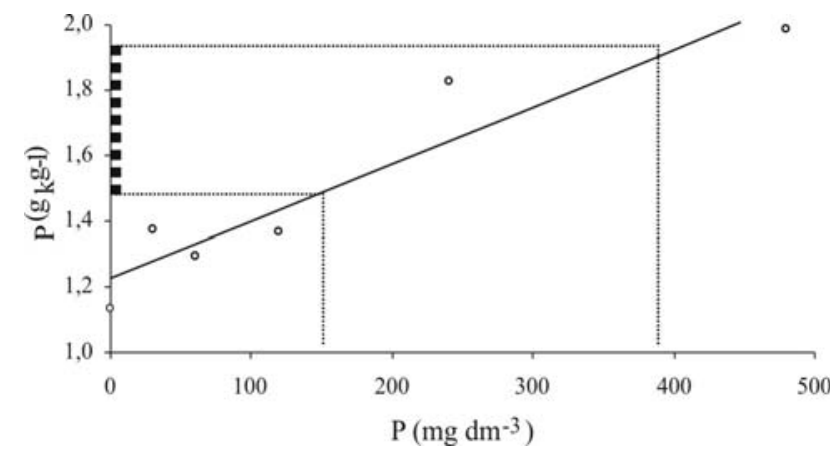

FIGURA 3- Nível crítico foliar de P em mudas de umbuzeiro.

\section{CONCLUSÕES}

1- A dose de $281 \mathrm{mg} \mathrm{dm}^{-3}$ de Pé indicada para a produção de mudas de umbuzeiro em Latossolo Vermelho distroférrico.

2- Mesmo quando bem nutrido em $\mathrm{P}$, o umbuzeiro apresentou maior produção de matéria seca do sistema radicular do que na parte aérea.

3- A faixa crítica de P nas folhas das mudas do umbuzeiro é de 1,52 a $1,91 \mathrm{~g} \mathrm{~kg}^{-1}$.

\section{REFERÊNCIAS}

BONFIM, E. M. S.; FREIRE, F. J.; SANTOS, M. V. F.; SILVA, T. J. A.; FREIRE, M. B. G. S. Níveis críticos de fósforo para Brachiaria brizantha e suas relações com características físicas e químicas em solos de Pernambuco. Revista Brasileira de Ciência do Solo, Viçosa, v. 28, n. 2, p. 281-288, 2004.

CARVALHO, J. G.; GONÇALVES, F. C.; NEVES, O. S. C.; GONÇALVES, S. M.; CLEMENTE, F. M. T. Caracterização de sintomas visuais deficiências de macronutrientes em mudas de umbuzeiro.In: CONGRESSO BRASILEIRODE FRUTICULTURA, 18., Florianópolis. Anais... Florianópolis-SC, 2004. 1 CD-ROM.

CARVALHO, J. G.; NEVES, O. S. C. Umbuzeiro (Spondias tuberosa Arr. Cam.). Lavras: Editora UFLA, 2004. 60 p.

FERNANDES, L. A.; FURTINI NETO, A. E.; FONSECA, F. C.; VALE, F. B. do. Crescimento inicial, níveis críticos de fósforo e frações fosfatadas em espécies florestais. Pesquisa Agropecuária Brasileira, Brasília, v. 35, n. 6, p. 1191-1198, 2000.

FERREIRA, D. F. Análises estatísticas por meio do SISVAR (Sistema para Análise de Variância) para Windows 4. 0. In: REUNIÃOANUALDAREGIÃOBRASILEIRADASOCIEDADE INTERNACIONAL DE BIOMETRIA, 45., 2000, São Carlos. Anais... São Carlos: UFSCar, 2000. p. 255-258.

GONDIM, T. M. S.; SILVA, H.; SILVA, A. Q.; CARDOSO, E. A. Período de ocorrência de formação de xilopódios em plantas de umbu (Spondias tuberosa Arr. Cam. ) propagadas sexualmente e assexuadamente. Revista Brasileira de Fruticultura, Cruz das Almas, v. 13, n. 2, p. 33-38, 1991.
GUPTA, R. K.; SINGH, R. S.; GUPTA, N.; YADAV, A. S. Effect of phosphorus application on the transformation of iron in soil and iron nutrition of rice under two soil moisture regimes. Journal Indian Society Soil Science, New Delhi, v. 30, n. 1, p. 58-62, 1982.

MALAVOLTA, E.; VITTI, G. C.; OLIVEIRA, S. A. Avaliação do estado nutricional das plantas: princípios e aplicações. 2. ed. Piracicaba: Potafos, 1997.319p.

MARSCHNER, H. Mineral nutrition of higher plant. $2^{\text {nd }} e d$. San Diego: Academic Press, 1995. 889 p.

NASCIMENTO, C. E. de S.; SANTOS, C. A. F.; OLIVEIRA, V. R. de. Produção de mudas enxertadas de umbuzeiro (Spondias tuberosa Arruda). Petrolina: EMBRAPA-CPATSA, 2000. 13 p. (Circular técnica, 48).

NEVES, O. S. C. Nutrição mineral e crescimento de mudas de umbuzeiro (Spondias tuberosa Arr. Cam.), em solução nutritiva, em função de níveis de salinidade. 2003. 70 f. Dissertação (Mestrado em Solos e Nutrição de Plantas) - Universidade Federal de Lavras, Lavras, 2003.

NEVES, O. S. C.; BENEDITO, D. S.; MACHADO, R. V.; CARVALHO, J. G. Crescimento, produção de matéria seca e acúmulo de $\mathrm{N}, \mathrm{P}, \mathrm{K}, \mathrm{Ca}, \mathrm{Mg}$ e $\mathrm{S}$ na parte aérea de mudas de andiroba (Carapa guianensis Aubl.) cultivadas em solo de várzea, em função de diferentes doses de P. Revista Árvore, Viçosa, v. 28 , n. 3, p. 343-349, 2004a.

NEVES, O. S. C.; CARVALHO, J. G.; HOJO, R. H. Nível ótimo de saturação por bases para mudas de umbuzeiro cultivadas em latossolo vermelho distroférrico. In: REUNIÃO BRASILEIRA DE FERTILIDADE DO SOLO E NUTRIÇÃO DE PLANTAS, 26., REUNIÃO BRASILEIRA SOBRE MICORRIZAS, 10., SIMPÓSIO BRASILEIRO DE MICROBIOLOGIA DO SOLO, 8., REUNIÃO BRASILEIRA FERTIBIO, 2004b, Lages. Anais...

RAIJ, B. van. Fertilidade do solo e adubação. São Paulo: Ceres, Potafos, $1991.343 \mathrm{p}$.

SANTOS, H. Q. Níveis críticos de fósforo no solo e na planta para gramíneas forrageiras tropicais, em diferentes idades. 1999. 80 f. Dissertação (Mestrado em Zootecnia) - Universidade Federal de Viçosa, Viçosa, 1999.

SILVA, H.; SILVA, A. Q. da; ROQUE, M. L.; MALAVOLTA, E. Composição mineral do umbuzeiro (Spondias tuberosa Arr. Cam.). In: CONGRESSO BRASILEIRO DE FRUTICULTURA, 7., 1983, Florianópolis. Anais... Florianópolis: SBF/EMPASC, 1984. v. 4, p. 1129-1134.

SILVA, H.; SILVA, A. Q.; OLIVEIRA, A. R.; CAVALCANTE, F. B. Algumas informações pomológicas do umbuzeiro da Paraíba. II. Características tecnológicas. In: CONGRESSO BRASILEIRO DE FRUTICULTURA, 9., 1987, Campinas, SP. Resumos... Campinas: SBF, 1987. v.1, p. 691-696. 